\title{
The Grocery Trolley Race in Times of Covid-19: Evidence from Italy
}

\author{
Emanuela Ciapanna ${ }^{1} \cdot$ Gabriele Rovigatti $^{1}$
}

Received: 30 August 2021 / Accepted: 13 February 2022 / Published online: 3 March 2022

(c) The Author(s) under exclusive licence to Società Italiana di Economia (Italian Economic Association) 2022

\begin{abstract}
We study the effects of the containment measures imposed by the Italian Government during the first wave of the Covid-19 pandemic on sales of the retail trade sector, focusing on different types of grocery chain stores. We document a sustained growth in revenues for storable products, beginning right before restrictions on mobility were introduced, and lasting throughout the whole lockdown period. The surge has been driven by the dynamics of smaller outlets, located in urban areas and closer to the city centre, while hypermarkets experienced a drop, probably relating to their more peripheral position. Thanks to the remarkable granularity of the Nielsen scanner data and the staggered implementation of restrictions across regions, we causally identify the short-term effects of mobility constraints on outlets' sales. According to our estimates, large grocery stores in areas subject to lockdown measures earned revenues around $10 \%$ lower than their control group did. In view of the protraction of the pandemic and the need for the Government to continue managing the containment of infections, our study helps quantifying the costs for the economy of mobility restrictions, also highlighting possible distortions arising among different categories of outlets.
\end{abstract}

Keywords Covid-19 · Grocery retail trade C Consumption hoarding · Mobility restrictions · Contagion risk

JEL Classification D12 · D18 · I30

\footnotetext{
We would like to thank Federico Cingano, Silvia Giacomelli, Sauro Mocetti, Sergio Santoro, and participants to the Bank of Italy Lunch seminar for useful suggestions. We are also indebted to Nicola De Carne (Nielsen) for data assistance. The views expressed here are our own and do not necessarily reflect those of the Bank of Italy.
}

$凶$ Gabriele Rovigatti

gabriele.rovigatti@bancaditalia.it

Emanuela Ciapanna

emanuela.ciapanna@bancaditalia.it

1 DG Economics, Statistics and Research, Bank of Italy, Rome, Italy 


\section{Introduction}

Italy has been among the first European countries to experience a widespread diffusion of the Covid-19, as well as one of the most hit in terms of deaths during the first wave. Since early March 2020, in order to contain the pressure on the overloaded healthcare system, several measures have been put in place by the Government under the guiding principle of social distancing to limit individuals' exposure to the virus in the workplace and in public spaces. Productive activities deemed 'non-essential' and suspended by the Prime Minister's Decree (DPCM) of 22 March 2020 until May 4th represented about one third of total value added, with percentages of up to around two thirds for the accommodation and catering services component and almost $100 \%$ for recreational activities. The impact of the pandemics on the various economic sectors, also due to unprecedented fall in demand, has been uneven. The immediate effects have been particularly severe in manufacturing, transports, catering, accommodation, recreation and culture, personal services, and in large swathes of retail trade. In March and April, the latter experienced a drop in sales of $23 \%$ compared to the corresponding period of 2019 , driven by the severe decrease in the non-food compartment ( $-45 \%)$. Instead, the food sub-sector outperformed, registering an overall increase of $5 \%$ in sales year on year (Fig. 1).

The present analysis focuses on the effects of the Government restrictions to mobility, imposed in Italy between the end of February and the beginning of May 2020, on sales of fast moving consumer goods (FMCGs) in grocery non specialized stores,

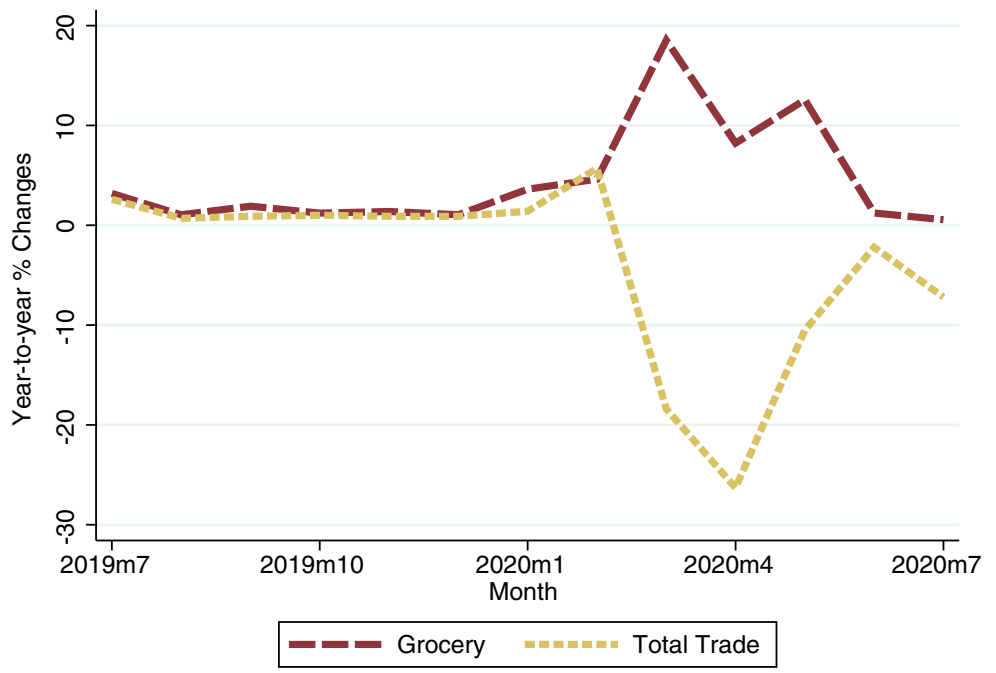

Notes: Year-on-year \% changes of total grocery sales (Nielsen, maroon line), and of total trade sector (Istat, yellow line).

Fig. 1 Sales in grocery and total retail trade; year-on-year changes (color figure online) 
namely hypermarkets, supermarkets, superettes and discounts. ${ }^{1}$ We document the dynamics of revenues in the period immediately before and during the lockdown, distinguishing between different types of stores, products and by geographical breakdowns. Our findings point to a sustained growth in sales in the 2-month period March-April 2020 of more than $16 \%$ with respect to the corresponding period in 2019, a considerable increase, comparable in magnitude to Christmas' sales peaks in "normal" times. The revenue surge during the restrictions is ascribable to both quantity and price increase, once accounting for the large composition effects at play. As of product categories, the most sustained dynamics concerned medical, pharmaceutical and food products. The type of outlet also represents an interesting dimension of heterogeneity throughout the spreading of the pandemics: restrained mobility favoured proximity stores of smaller size (superettes and smaller supermarkets), while penalizing larger ones (e.g. hypermarkets), generally located in more peripheral areas.

Along these lines, we propose an attempt to causally identify the effects of mobility restrictions on sales dynamics, by disentangling them from the general impact of fear of contagion risks. To this aim, we perform a difference-in-difference estimation, exploiting the time lapse between the institution of the first partial red zone, involving 10 municipalities within the Lodi province on February 23rd (treated group), and the total national lockdown, starting on March 9th (control group). Our results indicate that during the partial lockdown week, large grocery chain stores (super and hypermarkets) in the treated province registered revenues around 10\% lower than those of their control group. The effect is stronger for larger stores (e.g. hypermarkets), more exposed to mobility restrictions, due to their peripheral location, and for "less essential goods", such as cosmetics and alcoholic beverages ( -19 and $-12 \%$ respectively). The temporary nature of such shocks - which peaked for all categories at the onset of the lockdown, just to slowly fade away when restrictions were lifted - traces their source back to Government restrictions, rather than being the signal of structural changes in the market structure. In view of the protraction of the pandemic and the need for the authorities to continue managing the containment of infections, our study has important policy implications: it provides an estimate of the costs (in terms of lost revenues) of anti-contagion interventions for a large sector of the economy, also highlighting possible distortions among different categories of outlets.

Our results prove robust to different specifications. In particular, by exploiting the quasi-random location of the first Covid-19 clusters and the diffusion that ensued, we are able to split our sample according to the levels of contagion risk, and show that the latter does not bias our estimates. ${ }^{2}$

Our work is related to several recent empirical research contributions examining many aspects of the Covid-19 pandemic, and using different data sources. A first strand of literature analyses the effects of lockdown measures and contagion on consumers' behavior. Three notable studies for Denmark, Spain, and the US present

\footnotetext{
1 Fast-moving consumer goods, also known as packaged goods, are products that sell quickly at relatively low cost. FMCGs have a short shelf life because of high consumer demand (e.g., soft drinks and confections) or because they are perishable (e.g., meat, dairy products, and baked goods). These goods are purchased frequently, are consumed rapidly, are priced low, and are sold in large quantities. They also have a high turnover when they are on the shelf at the store.

2 See Diao et al. (2017) for details on the spatial difference-in-differences.
} 
evidence on the impact of Covid-19 on consumer spending. Andersen et al. (2020) use transaction-level bank account data from a large Danish bank to find a decline in spending - following the Covid-19 outbreak — which varies across product categories and correlates with Government's restrictions. Carvalho et al. (2020) utilise a large high-frequency point-of-sale transaction dataset from a major Spanish commercial bank to find large overall spending declines across various product categories, following a Government lockdown. Baker et al. (2020a, b) use transaction-level household financial data from a personal-finance website to observe a substantial increase in consumer spending as Covid-19 cases increase, followed by a significant decline in general spending. The authors also observe heterogeneity in spending responses across states (depending on the severity of the virus outbreak). Chronopoulos et al. (2020) examine consumer-spending responses to the onset and spread of the pandemics and the subsequent government-imposed lockdown in Great Britain. Based on data from a personal finance app, which aggregates all transactions from linked bank accounts and credit or debit cards, they find that overall consumer spending declined as the UK government lockdown became imminent and has continued to decline since, although with some heterogeneity by age, gender, and income level. Our work is especially related to two other recent contributions. The first one is an article by O'Connell et al. (2020), where the authors use household-level scanner data for the UK to analyse purchase dynamics during the pandemics. They document large spikes in spending on storable products in the 4 weeks preceding the lockdown, particularly visible for FMCGs. The second piece of literature is the work by Goolsbee and Syverson (2020), which proposes a causal estimate of the effects of the shutdown policy conditions at the county and city level in the US on foot traffic, a proxy for economic activity. The results indicate that legal shutdown orders have accounted for a modest share of the massive overall changes in consumer movements. However, Goolsbee and Syverson (2020) consider how often people visit shops rather than how much do they actually spend, which makes their findings perfectly compatible with a surge in grocery stores' revenues overall.

Compared to the the aforementioned contributions, the present article adopts a somewhat different perspective. In fact, our focus is on outlets' performance (revenues and sold quantities) rather than on consumers' preferences and spending behavior. The latter is clearly a fundamental driving force within the analysis, yet our main objective is to disentangle the effect on the observed dynamics of Government restrictions (imposed by decree with different timing) from those associated to contagion risks fear.

The original contribution of our analysis is twofold: on the one hand, with respect to the aforementioned literature, we propose an attempt of causal identification of the lockdown effect on sales, on the other hand, our estimation method presents some elements of novelty in the designing of distance-depending control groups, borrowed from the spatial econometrics techniques (Diao et al. 2017).

The paper is structured as follows. In Sect. 2 we present the institutional setting and the timing of the Covid-19 restriction measures in the different Italian regions, in Sect. 3 we outline the dataset and document revenues dynamics across broad sets of outlet types, regions and products. In Sect. 4 we propose our identification analysis of the the effects of restricted mobility on revenues dynamics, and discuss our results. A 
final section concludes. Robustness checks, additional tables and figures are relegated to the Appendices.

\section{Institutional Background}

In this section we provide a general description of the relative weight of the grocery chain-store sector in Italy, with particular reference to market share dynamics of the different types of outlets in the last decade with a geographical detail. Successively, we present the timing of the Covid-19 crisis from its onset in late February, until the end of the restrictions period and we show how the containment measures have differently affected the grocery retail sector, depending on store type as well as on geographical location.

\subsection{The Grocery Chain-Store Sector in Italy}

In the food sector alone, the market share of modern distribution (grocery retail chain stores) represents $74.5 \%$, in Italy, corresponding to about 88 billion of food consumption. The number of outlets has decreased of around $11 \%$ within the last decade, from around 29 thousand in 2009 to 26 thousand in 2018, due to the sharp reduction in smaller-size shops, having a sales area between 100 and $400 \mathrm{~m}^{2}(-26.6 \%)$, partially offset by the expansion of discounters $(+24.2 \%)$. Supermarkets are also growing, albeit to a less extent (1\%), while hypermarkets are downsizing (Fig. 2). Grocery large-scale retail in Italy remains one of the most atomised markets in Europe. The top five operators represent just over half of the market (51.8\%) while in countries such as Germany, France and the United Kingdom the share is between 75 and $80 \%$. A closer look, however, unveils local as well as structural differences, which characterize both the market structure and its evolution-including different types of dynamic responses to shocks.

The most striking difference between geographical areas concerns the distribution of outlet types. In Fig. 3a, we report the relative market shares of store categories by NUTS1 in 2019. ${ }^{3}$ While Supermarkets are the best-selling format in most of the country, the market share of large-scale stores strictly depends on the macro-area, being very popular in the North West, while representing only the $10 \%$ of the market in Southern regions - where consumers seem to prefer smaller-scale stores. The wide gap in Discount market shares-more than $10 \%$ between the South and the North West-reflects crucial differences in market structure and consumer habits toward the low price policies followed in those stores. In panel (b), we report the dynamics of the average store size between 2003 and 2017: in line with the (static) market share figures, in the Northwest stores are bigger, and have been growing at a higher rate than those located in other areas of the country, since the early 2000s.

\footnotetext{
3 The distinction between hypermarkets, supermarkets and superettes hinges on the store size, and more specifically if the facilities are bigger than 2500, 1500 or $450 \mathrm{~m}^{2}$, respectively. Discounts, are specialized in private label and non branded products.
} 

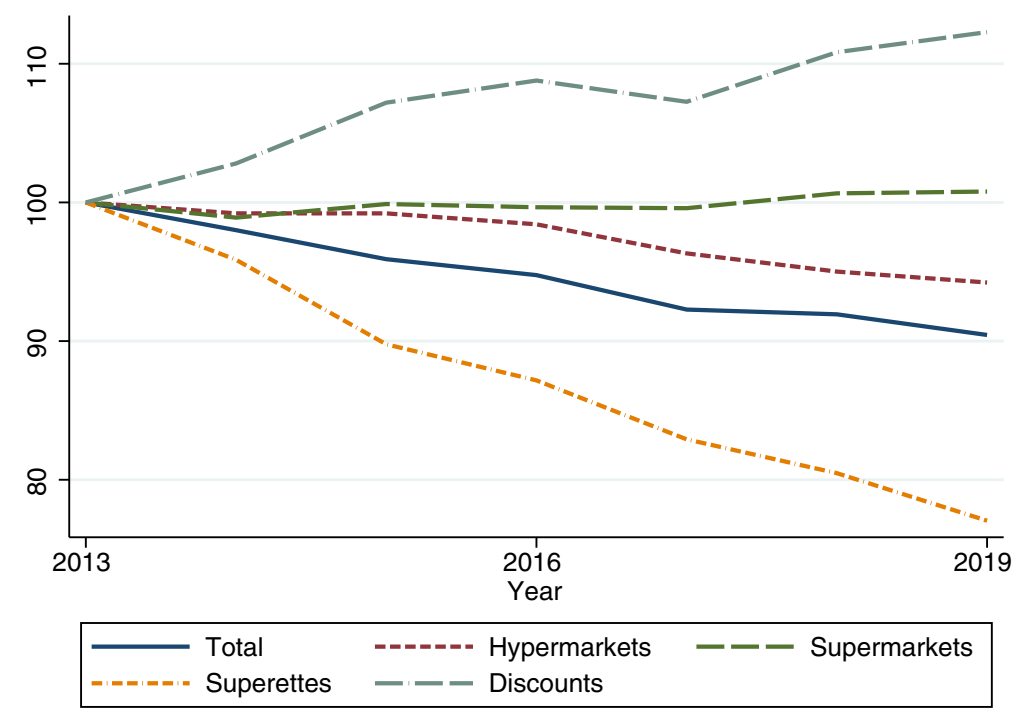

Notes: Number of grocery stores per type in Italy, 2013-2019. Sources: Federdistribuzione, Economic Development Ministry, Gnlc Nielsen, Tradelab.

Fig. 2 Evolution in the number of outlets in the grocery retail sector in Italy (index $2013=100$ ) (color figure online)

(a) Market Shares by type in \%, 2019

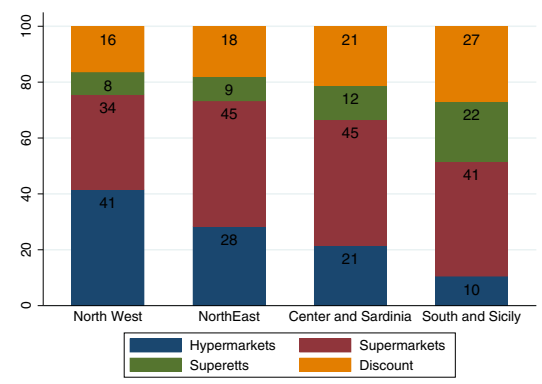

(b) Average Size in $m^{2}, 2013-2017$

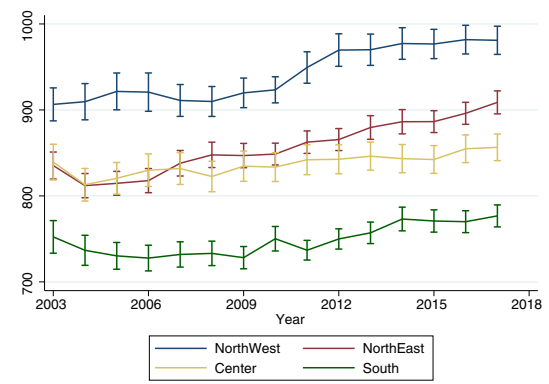

Notes: (a) Market shares per distributive category and macroarea in 2019. hypermarkets are facilities bigger than 2,500 sq. meters, supermarkets bigger than 1,500, and superettes are bigger than 450. Discounts sell different product brands. (b) Average store size per municipality, aggregated at macroarea. Authors' elaborations on Nielsen data.

Fig. 3 Market shares and average market size (color figure online)

Not surprisingly, there is a very strong and positive association between the number of outlets and population density $(\rho=0.95)$ on the one hand, and total sales area ( $\rho=0.45$ ) on the other hand. We also find a negative correlation between population density and the presence of large sales surfaces $(\rho=-0.13)$. In fact, hypermarkets arise mostly in peripheral areas, which implies the need for customers to drive to the store location (for a detailed discussion on the topic, see Viviano et al. 2012). 


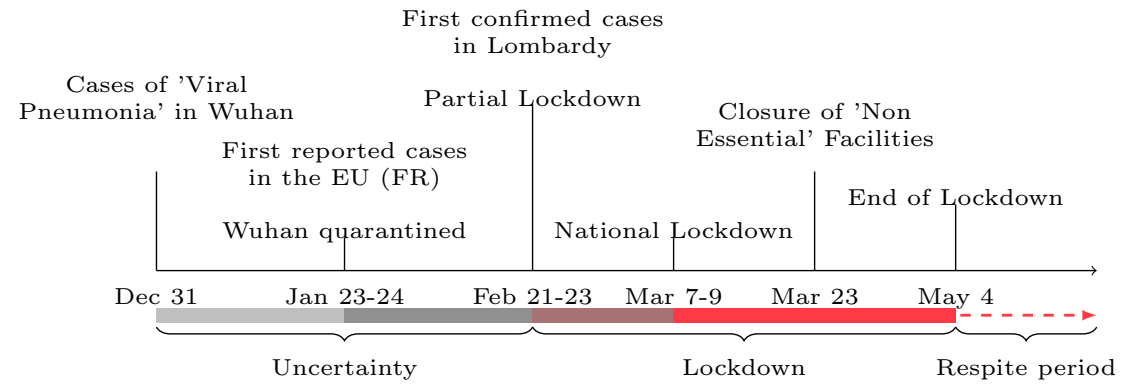

Notes: Timeline of the Covid-19 pandemics evolution in Italy. Red areas correspond to partial/national lockdown periods.

Fig. 4 Covid-19 first wave Timeline in Italy (color figure online)

As we show in the next sections, this feature helps us to explain the more modest dynamics in sales registered by this category of stores compared to the others during the period of mobility restrictions, which we exploit for identification purposes later in the discussion.

\subsection{The Timing of the Covid-19 Crisis}

Figure 4 depicts the main phases of the Covid-19 crisis. The first acknowledgment of the existence of a suspect "viral pneumonia" cluster of cases in Wuhan, China, dates back to December 31, 2019, and was closely followed by the first reported cases in the EU, and by the lockdown imposed to the Hubei region in mid-January. In Italy, the first reported cases, not directly linked to the Wuhan cluster, date back to mid-February and were detected in Lombardy. On February 23, 2020, the Government declared the first-partial-lockdown, involving 10 municipalities in the Lodi province, which were quarantined to prevent the spread of contagion. Soon after, the sudden increase in the number of infected patients, the pressure on the Intensive Care Units (ICUs) in the most affected areas, and the rise in the count of Covid-19-related deaths prompted the authorities to take unprecedented actions. On March 7 2020, all of Lombardy and 14 additional provinces were quarantined. ${ }^{4}$ After only 48 h, on March 92020 , the whole Italian territory was placed under lockdown. Moreover, the closure of all "non-essential" activities (including bars, cinemas, restaurants) was imposed, in order to ensure social distancing, and reduce the rate of contagion. Covid-19 cases started to decline in May 2020, thanks to the 2-months lockdown. Freedom of movements was re-established on May 4, and other not essential activities re-opened later in the month, putting an end to the so-called "phase 1" of the first wave to enter "phase 2", or Respite period (for further details regarding the evolution of the pandemics and the relative containment measures, see Appendix A). After the summer lull, the virus regained strength in late September, giving rise to the second wave.

\footnotetext{
4 More specifically, the provinces of Parma, Piacenza, Reggio Emilia, Rimini, Pesaro and Urbino, Venezia, Padova, Treviso, Asti, Alessandria, Novara, Vercelli, and Verbano-Cusio-Ossola in four regions (EmiliaRomagna, Piedmont, Veneto and Marche).
} 


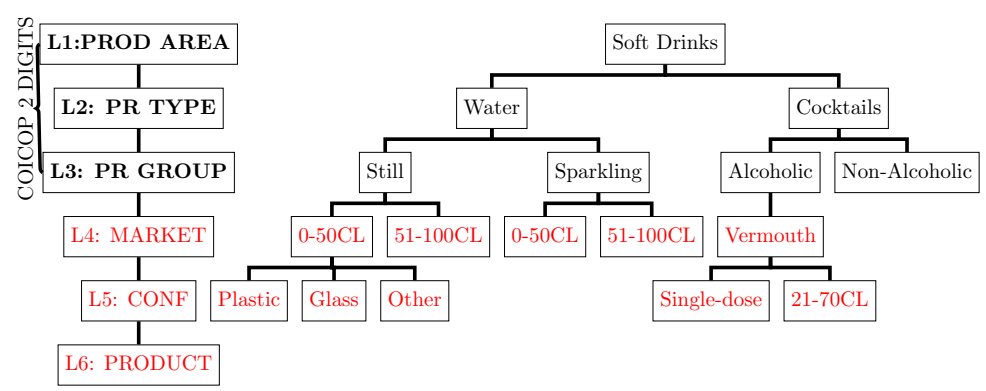

Notes: Nielsen/ECR scanner data structure, split in information available (black font) and missing (red font) in our dataset.

Fig. 5 Data structure: the Nielsen Data and the ECR classification (color figure online)

\section{Data}

This section presents the data sources that are employed throughout the analysis and the first descriptive evidence regarding the dynamics of grocery stores' revenues following the introduction of Government restrictions in place between early March and the first week of May 2020 in Italy. We employ NUTS1 and NUTS3 level scanner data on revenues and sold quantities, collected by Nielsen and covering about $85 \%$ of total grocery chain stores in Italy. ${ }^{5}$ The Nielsen scanner data are structured according to the general classification provided by the Efficient Consumer Response (ECR) community, used for category management by both industrial and distribution companies. The ECR classification involves a hierarchical, multi-layer structure, with increasingly granular and more specific clusters of products. In the analysis, we match its broader categories (Product Area) with corresponding Classification of Individual Consumption by Purpose (COICOP, UN Statistical Division, 2018) classes. Despite the differences in the classification scope-distributive and consumption-based, respectively-the two overlap pretty well.

In Fig. 5, we report an example of the Nielsen data structure alongside the general nomenclature of the ECR classification. In particular, out of the 6 layers available, our data is aggregated at L3 (product group, black font) - as a result, we are able to track down the dynamics of the granular products, but we miss potentially interesting information related to the marketability and packaging (L4 and L5, respectively), as well as individual product information like brand, producer, etc. (red font layers), which all appear aggregated and not distinguishable.

We employ weekly data for 462 product categories, sold in Italy from January 1, 2018 to October 30, 2020. The NUTS1-level data (North-West, North-East, Center and Sardinia, and South and Sicily) further identify the type of store, whereas the NUTS3level one (province) only accounts for total sales in larger outlets (i.e. all the super and hypermarkets). In Table 1 we describe the two datasets (Channels for NUTS1-level, and Provinces for NUTS3) in terms of coverage, granularity, and variables reported. Based on the COICOP, we identify 19 products at the most granular 4-digits level,

\footnotetext{
5 The dataset covers sales for the universe of hypermarkets and supermarkets, $90 \%$ of discounts and around $67 \%$ of superettes.
} 
Table 1 Nielsen: available data

\begin{tabular}{lll}
\hline & Channels & Provinces \\
\hline $\begin{array}{l}\text { Time dimension } \\
\text { Frequency }\end{array}$ & Weekly & Weekly \\
Coverage & Jan 1, 2018-today & Jan 1, 2018-today \\
Granularity & & \\
ECR & L3 & L3 \\
Geography & NUTS-1 and Store Type & NUTS-3 and H+S \\
Coverage & Big-box Sector & Big-box Sector \\
Variables & & \\
Measured & Revenues and Quantity (P*Q e Q) & Revenues and Quantity (P*Q e Q) \\
Approximate* & Prices $(\mathrm{P})$ & Prices $(\mathrm{P})$ \\
\hline
\end{tabular}

* The computation of weekly prices $\hat{P}=P * Q / Q$ is influenced by (i) changes in the composition of product baskets, (ii) discounts and offers, and (iii) the product formats purchased.

Available Nielsen dataset description and main characteristics

Table 2 Revenues per product

\begin{tabular}{|c|c|c|c|c|c|}
\hline & (1) & (2) & (3) & $\begin{array}{l}\text { (4) } \\
\text { T-tests }\end{array}$ & (5) \\
\hline & Treated & All controls & Lomb Controls & $\begin{array}{l}\Delta_{A-T} \\
(2)-(1)\end{array}$ & $\begin{array}{l}\Delta_{L-T} \\
(3)-(1)\end{array}$ \\
\hline Food & $\begin{array}{l}2937.9 \\
(325.8)\end{array}$ & $\begin{array}{l}6274.5 \\
(8347.9)\end{array}$ & $\begin{array}{l}13909.1 \\
(17,428.4)\end{array}$ & $\begin{array}{l}3336.6^{* * *} \\
(79.37)\end{array}$ & $\begin{array}{l}10971.2^{* * *} \\
(455.4)\end{array}$ \\
\hline Soft drinks & $\begin{array}{l}430.5 \\
(37.97)\end{array}$ & $\begin{array}{l}922.2 \\
(1120.6)\end{array}$ & $\begin{array}{l}1935.4 \\
(2296.2)\end{array}$ & $\begin{array}{l}491.7^{* * *} \\
(10.50)\end{array}$ & $\begin{array}{l}1504.9^{* * *} \\
(59.97)\end{array}$ \\
\hline Alcoholics & $\begin{array}{l}266.8 \\
(45.96)\end{array}$ & $\begin{array}{l}578.7 \\
(849.0)\end{array}$ & $\begin{array}{l}1377.9 \\
(1833.1)\end{array}$ & $\begin{array}{l}311.8^{* * *} \\
(8.489)\end{array}$ & $\begin{array}{l}1111.1^{* * *} \\
(47.96)\end{array}$ \\
\hline Household & $\begin{array}{l}211.5 \\
(21.72)\end{array}$ & $\begin{array}{l}374.1 \\
(493.6)\end{array}$ & $\begin{array}{l}864.4 \\
(1062.1)\end{array}$ & $\begin{array}{l}162.6^{* * *} \\
(4.765)\end{array}$ & $\begin{array}{l}652.9^{* * *} \\
(27.76)\end{array}$ \\
\hline Medical appl & $\begin{array}{l}26.85 \\
(5.552)\end{array}$ & $\begin{array}{l}47.17 \\
(68.53)\end{array}$ & $\begin{array}{l}117.3 \\
(149.8)\end{array}$ & $\begin{array}{l}20.32^{* * *} \\
(0.765)\end{array}$ & $\begin{array}{l}90.47^{* * *} \\
(3.933)\end{array}$ \\
\hline Personal & $\begin{array}{l}419.2 \\
(29.70)\end{array}$ & $\begin{array}{l}776.8 \\
(1024.5)\end{array}$ & $\begin{array}{l}1772.6 \\
(2207.7)\end{array}$ & $\begin{array}{l}357.6^{* * *} \\
(9.487)\end{array}$ & $\begin{array}{l}1353.4^{* * *} \\
(57.63)\end{array}$ \\
\hline
\end{tabular}

Elaborations on Nielsen data. Descriptive statistics: average weekly revenues per product group and provinces groups - treatment (i.e., Lodi, in column 1), all other provinces (2), and other Lombardy provinces (3). In columns 4 and 5 we report the results of t-tests on the difference of the means between the control and treatment municipalities

further aggregated into seven 2-digits clusters: food-which is the main segment, soft drinks, alcoholics, household equipment, medical appliances, and personal care supplies (see Table 2).

For exposition purposes, in what follows we distinguish three sub-periods along the first wave of the Covid-19 crisis: Anticipation (February 1 until March 8 2020), 


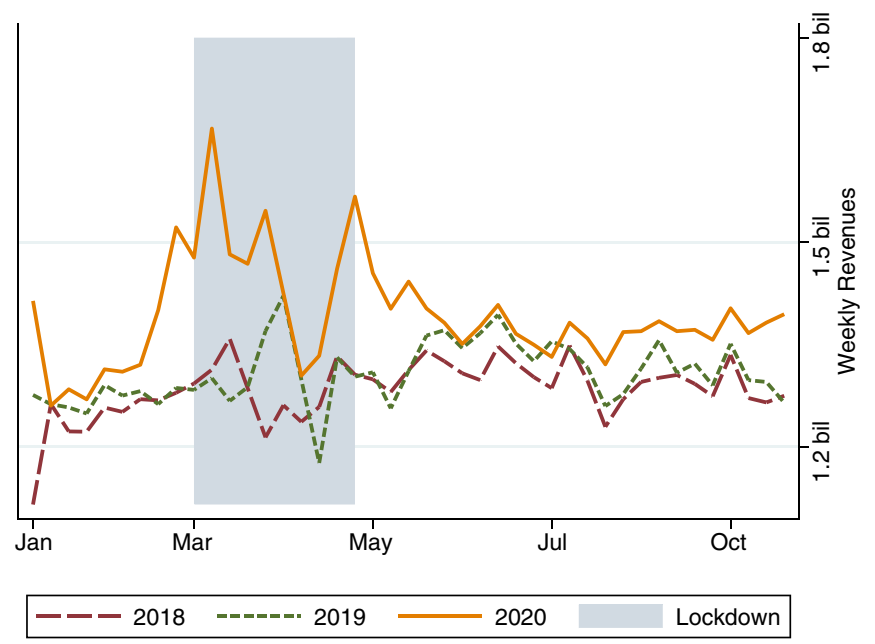

Notes: Italian grocery retail sector total weekly revenues, 2018-2020 - Nielsen data. In each series, we exclude Easter week. The shaded area corresponds to the weeks of the national lockdown in 2020 .

Fig. 6 Total revenues 2018-2020 (color figure online)

Lockdown (March 8 until May 4 2020), and finally the Respite, from the end of the lockdown to October 30 2020. In Fig. 6 we report the overall sum of revenues per week in 2018 (maroon dashed), 2019 (green dotted), and 2020 (yellow solid) for the whole sample in the period January-October. The graph highlights the presence of a structural break in the 2020 series, coinciding with the first wave of the pandemics, starting around the last week of February (anticipation period), until the beginning of May, which gradually vanishes throughout the Summer (respite period). The peak is registered on March 8th, i.e. the first week of national lockdown. Looking at revenues dynamics, the year on year growth rate of weekly revenues ${ }^{6}$ at the national or NUTS1regional level (and/or by product categories), writes:

$$
r\left(y_{w}\right)=\frac{y_{w}-y_{w-52}}{y_{w-52}} * 100
$$

In Fig. 7a, we report the time series of $r\left(y_{w}\right)$ from October, 2019 and October, 2020, for the whole country. The series presents two spikes: the first coincides with the national lockdown on March 8, and the second with the end of the lockdown-i.e., the first week of May, 2020. The plot, however, suggests that the lockdown regulatory measures did not fully channel the increase in revenues: the "excess" demand (i.e., precautionary spending) appeared already on early February, as the first news of the pandemics outbreak started spreading (consumption hoarding), and abnormal revenues ceased only in June, when mobility across regions was fully re-established, just to reemerge with the onset of second wave in September.

\footnotetext{
6 The year-on-year rate is defined as the percentage change between sales in week $w$ of revenues $y$ with respect to revenues of the corresponding week 1 year before (i.e., $y_{w-52}$ ).
} 
(a) Countrywide

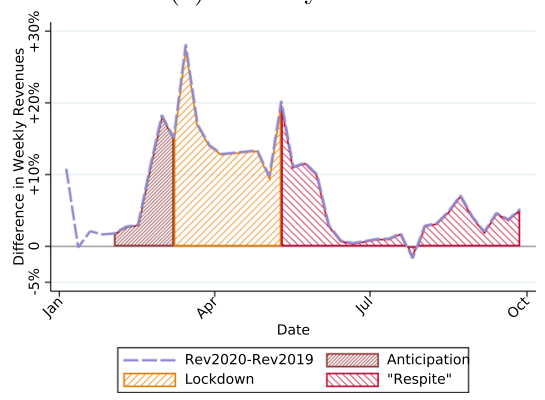

(c) NUTS1 Regions

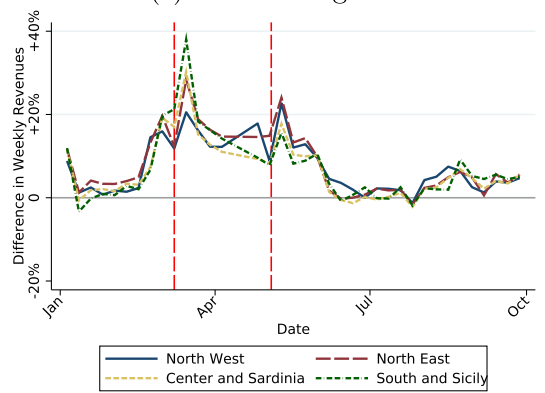

(b) Outlet type

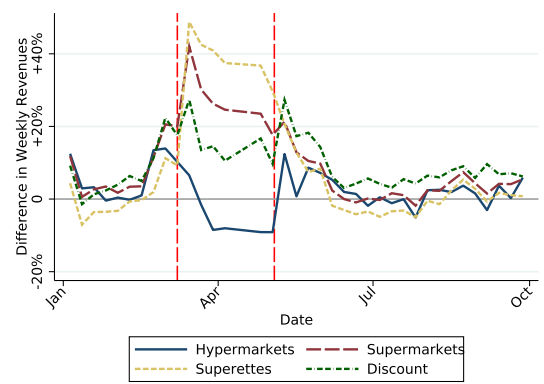

(d) Products

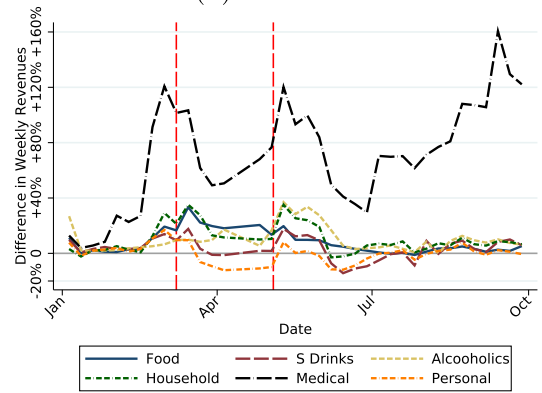

Notes: Year-on-year \% changes in revenues. (a) countrywide, split in subperiods - Anticipation in maroon, Lockdown in yellow, and Respite in red; (b) divided by outlet type: hypermarkets (solid blue), supermarkets (dashed red), superettes (dotted yellow) and discounts (dotted green); (c) divided by NUTS1 regions: North West (solid blue), North East (dashed red), Center and Sardinia (dotted yellow), and South and Sicily (dotted green); (d) divided by product groups: Food (solid blue), Soft Drinks (dashed red), Alcoholics (dotted yellow), Household products (dotted green), Medical appliances (dashed black), and Personal goods (dotted orange). The vertical, dashed lines mark the starting and end date of the lockdown.

Fig. 7 Time series of $r(y)$, Weekly revenue growth 2019-2020 (color figure online)

Despite the acceleration in revenue growth registered in aggregate terms, the lockdown effect appears to be composite, depending on store types. In panel (b) we report the same $r\left(y_{w}\right)$ series by outlet category: while the anticipation effect generates common upward trends, these diverge as soon as the restrictions to the mobility take place. While medium- and small-scale stores, including Discounts, reach unprecedented levels of revenues, with +20 to $+40 \%$ increases with respect to the same week of 2019, hypermarkets experienced negative fluctuations for the whole lockdown subperiod. We argue that a similar diverging pattern, far from being the result of changes in consumption habits, is rather attributable to the more peripheral position of large retail surfaces, less easily accessible throughout the time lapse of mobility restrictions. Indeed, especially in smaller municipalities, hypermarket customers were unable to drive beyond municipal boundaries and were induced to shop in vicinity outlets (generally superettes or specialized stores), within few hundreds meters from their homes. This intuition finds further confirmation in the sudden reversion of the trend to the old habits immediately following the end of lockdown (see the positive spike since May 4). 
Apparently, as shown in panel (c), the same revenue patterns have been recorded all over the country, with only minor differences across NUTS1 regions. Finally, in panel (d), we exploit the 2-digit COICOP classification to show how rather diverging trends emerge across products: while relatively important product clusters (in terms of total market share), such as food and household appliances experienced sizeable increases, the personal products were negatively affected by the lockdown. Unsurprisingly, medical equipments (including masks, pharmaceuticals, etc.) recorded unprecedented peaks both during and after the lockdown period (further details about the lockdown effects, distinguishing between geographical areas, product/outlet types and price/quantity impact are relegated to Appendix B).

\section{Identifying the Lockdown Effect}

In this section, we attempt to identify the causal impact of the mobility restriction measures adopted during the first wave on sales of large grocery stores in Italy. We first describe our empirical strategy, which exploits the gradual entry into force of the provisions by different geographical areas; then we report our results and discuss their significance and limitation. Finally, we conduct a battery of robustness checks to corroborate our evidence. The present analysis is based on NUTS3 data, which are available for the universe of large stores only (as stated in Sect. 3), so all our results in this section solely apply to this sub-category.

\subsection{Empirical Strategy}

The partial lockdown imposed on ten municipalities within the province of Lodi on February 23, 2020, provides an exogenous variation in the treatment status that we use to estimate the causal lockdown effects on grocery stores revenues. More specifically, we exploit the fact that the red zone-nearly the whole province-had been isolated from the rest of Lombardy with the prohibition for its citizens of moving from home, except for reasons of emergency and for the supply of essential and basic necessities. We propose the following difference-in-difference specification:

$$
y_{i p t}=\alpha+\beta \text { treatment } t_{i p t}+\tau_{t}+\gamma_{i p}+\epsilon_{i p t}
$$

where our outcome variable $y$ is the log of revenues for product $i$ in province $p$ at week $t$; treatment $t_{i p t}$ is an indicator function for products sold in the Lodi province after February 23, 2020, while $\tau_{t}$ and $\gamma_{i p}$ are time and province/product fixed effects, respectively. $^{7}$

In Fig. 8a, we plot revenues dynamics (index February 5, 2020=1) for the treatment (solid blue line) and the control group (dashed maroon line) — the latter including all

\footnotetext{
7 Given that the treatment period goes from February 23 to March 8 (3 points in time given the weekly frequency of our data), for the sake of consistency in our exercise, we consider the 3 weeks before the restrictive measures are enforced, i.e. form the week of February 1st to the first week of lockdown.
} 
(a) Revenues - trends per group

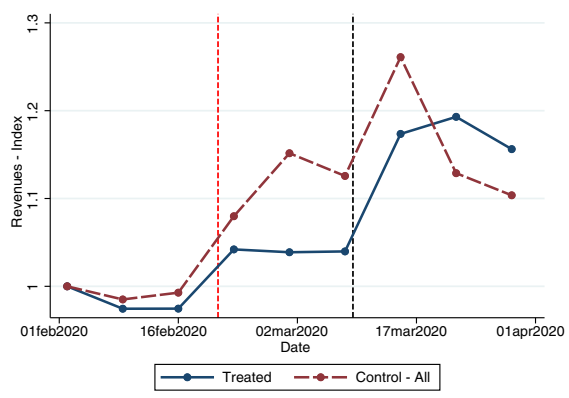

(b) Mobility Patterns

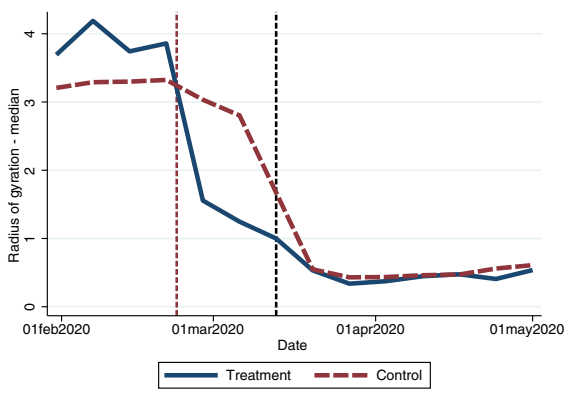

Notes: (a) Revenues indexed at February 1, 2020, reported for the treatment group (Lodi, solid blue), averaged across the control group provinces for the baseline control (Control - All, dashed maroon), and across all Lombardy provinces but Lodi (dashed green). (b) Within-province mobility patterns in Lodi (solid blue) and averages across control group provinces (dashed maroon). The mobility is proxied through the median value of the radius of gyration - Pepe et al. (2020).

Fig. 8 Pre-trends and mobility patterns (color figure online)

Italian provinces but Lodi. ${ }^{8}$ The plot confirms that there are no detectable pre-trends that differently affected the treatment and the control group. Moreover, despite the upward dynamics, the graph highlights how the treated units "catch-up" the level of spending of control units right after the national lockdown date (black dotted line). Figure 8b, depicts the within-province mobility for the treatment and the control group: in the time lapse between the treatment date (maroon vertical line) and the national lockdown (black vertical line), the mobility within the treated area decreased dramatically, lying well below the average level in control provinces. The gap was closed only when the national lockdown extended the same measures to the whole country.

The proposed model faces a few potential threats to the identification of the correct treatment effect, which we discuss below and address with a series of robustness checks - reported in the body of the paper below or in Appendix C.

First, and foremost, one could argue that our results are driven by the heterogeneous perceived risk of contagion in the two groups rather than by the different restrictions applied to treated and controls. The descriptive evidence shown in Fig. 8a, could induce to believe that the treatment affects provinces belonging to the control group(s) as well as Lodi, which would violate the main assumption for the validity of the differencein-differences identification-i.e., absent the treatment, the outcome of treatment and control groups would hold parallel. We argue that the regulatory intervention imposed on February 23, 2020 - the lockdown-had two main effects: on the one hand, it generated a wave of concern about contagion risk (signalling effect) that invested the whole country, and caused a spike of consumption hoarding for precautionary reasons (O'Connell et al. 2020). On the other hand, for quarantined municipalities only, it imposed strict constraints to personal mobility (mobility effect). As long as the extent of the signalling effect is the same for treated and control units, the proposed

\footnotetext{
8 In order to avoid the possibility of store detection, the Nielsen data only cover 87 provinces in Italy, out of 107. In most cases, the "missing" provinces are located in the Southern regions.
} 
(a) Total cases over 100,000 population

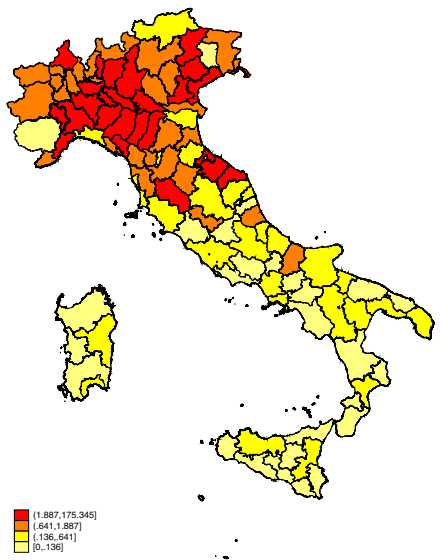

(b) Distance-based controls

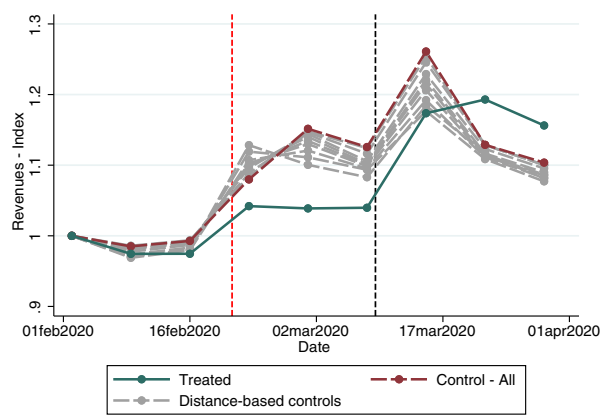

Notes: (a) Total Covid-19 identified cases between March and September, 2020, per 100,000 inhabitants at the province level (February/August, 2020). (b) Revenues indexed at February 1, 2020, reported for the treatment group (Lodi, solid blue), averaged across the control group provinces for the baseline control (Control - All, dashed maroon), and across all distance-based control groups (dashed grey).

Fig. 9 Covid incidence and distance-based trends (color figure online)

identification captures an unbiased estimate of the mobility effect. In other terms, we assume the lockdown effect to be a combination of two components, $\beta^{l o c k}=\beta^{\text {mob }}+$ $\beta^{\text {sign }}$, one affecting, by definition, the treated group only $\left(\beta_{\text {treatment }}^{\text {mob }}>0=\beta_{\text {control }}^{\text {mob }}\right)$ and captured by (2), whilst the other assumed equal for both groups $\left(\beta_{\text {treatment }}^{\text {sign }}=\right.$ $\beta_{\text {control }}^{\text {sign }}$, irrespective of the contagion risk faced. The latter assumption, though, has clear observable implications-i.e., control provinces facing higher contagion risk must not show significantly higher levels of revenues than control provinces with fewer contagions - that we empirically test in Sect. 4.3.

In order to correctly identify the impact of mobility restriction measures on total revenues, as distinct from the effect of perceived contagion risk, we also propose an exercise with distance-dependent control groups, whose size in terms of included provinces is an increasing function of the distance from the epicenter of contagion (i.e. the province of Lodi). Following the methodology proposed in Diao et al. (2017), we exploit the heterogeneous geography of the first wave of infections-which we report, in terms of total cases per 100,000 inhabitants within the province, in Fig. 9a. Most heavily affected provinces are located in the North-West, and in particular around Lodi (which is by far the worst case, with an incidence of around 175). The "quasiexogenous" geographical distribution of the starting clusters allows us to partition provinces into gradually less exposed units, depending on their physical distance from the epicenter. More specifically, we compute the distance between each province and Lodi, ${ }^{9}$ and use the deciles of the distance distribution to generate gradually narrower balls around the treated province. For each decile, all provinces whose centroid lies

\footnotetext{
9 In order to do that, we first compute the centroids for each province, then we generate a measure of distance, in kilometers, to the centroid of Lodi.
} 
within the relative ball belong to the control group. In Fig. 9b, we report the trends for each distance-based control group: all of them confirm the absence of any significant pre-trend. In addition, we run the baseline model excluding all provinces which share any boundary with Lodi: in this way, we are able to exclude from the analysis the units facing the highest (perceived) contagion risk.

Second, our analysis suffers from data limitations. In fact, the maximum degree of geographical detail available in the Nielsen data-set is NUTS3, i.e. the province level. On the other hand, the quarantine was imposed at the municipal level, for a subset of municipalities within the Lodi province. The latter account for $22 \%$ of the whole province population, and are home to more than $40 \%$ of sales area within the grocery retail sector, respectively. Provided that the data points in our treatment group include both the treated and a subset of control units, the estimated $\beta$ is downward biased by construction and attains a lower bound of the actual effect.

Third, the province of Lodi may have unique features possibly driving our results, and our model could be capturing them, rather than the lockdown effect. Italian provinces are in fact characterized by an extreme degree of heterogeneity. In this context, the very small size of the treatment group relative to the control raises similar concerns. In order to address both issues, we propose (i) an inverse propensity scoreweighted version of model (2) — which corrects for possible selection of treated units into the treatment, and (ii) a synthetic control group analysis, with province level data. Both exercises yield very robust, and statistically significant results (see Appendix C).

\subsection{Results and Robustness Checks}

Table 3 reports the results of the difference-in-differences estimation on total revenues (column 1, Baseline). Our results point to an impact of lockdown measures of around $10 \%$ lower revenues for grocery stores located in the red zone with respect to those located in areas not subject to mobility restrictions. These findings are remarkably robust to the choice of the model: columns 2 to 10 report the estimates using the distance-dependent control groups, increasingly more restrictive-from the 9th (corresponding to a radius of around $750 \mathrm{~km}$ around Lodi) to the 1st decile (which corresponds to a very narrow $64 \mathrm{~km}$ radius) —-with qualitatively the same estimates. These results provide a strong support to the correctness of our identification: irrespective of the level of contagion risk considered in the control group, in fact, the point estimate is relatively unaffected.

looseness-1In Table 4 we test the robustness of our results to different compositions of the control group, and for both total revenues (panel a) and within-province mobility (panel b). Column 2 reports the results obtained keeping in the control group only the provinces within the first decile of distance from Lodi, whereas in column 3 we implement a somewhat opposite approach and, focusing on the contiguity rather than the distance between provinces, we exclude from the sample all Lodi's neighbor provinces in order to avoid possible confounding effects coming from the contagion risk component (see next section for a more detailed analysis on the point). Finally, in columns 4 and 5 we split the sample according to macroareas (Center-South and 


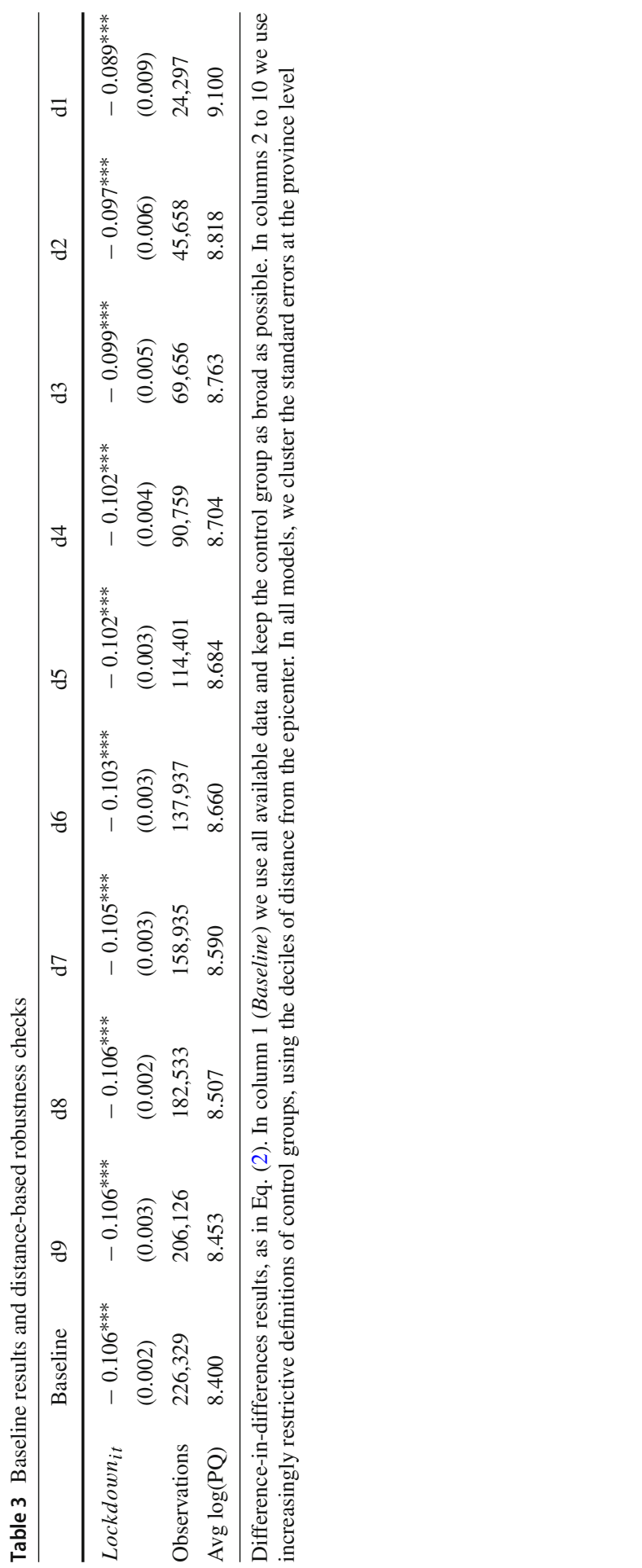


Table 4 Baseline results and distance-based robustness checks—revenues and mobility

\begin{tabular}{|c|c|c|c|c|c|}
\hline & Baseline & $\begin{array}{l}\text { Nearest } \\
\text { Neighbors }\end{array}$ & $\begin{array}{l}\text { No } \\
\text { Neighbors }\end{array}$ & $\begin{array}{l}\text { Lodi vs. } \\
\text { Center-South }\end{array}$ & $\begin{array}{l}\text { Lodi vs. } \\
\text { North }\end{array}$ \\
\hline \multicolumn{6}{|l|}{ (a) Revenues } \\
\hline Lockdown $_{i t}$ & $\begin{array}{l}-0.106^{* * *} \\
(0.003)\end{array}$ & $\begin{array}{l}-0.089^{* * *} \\
(0.009)\end{array}$ & $\begin{array}{l}-0.108^{* * *} \\
(0.004)\end{array}$ & $\begin{array}{l}-0.113^{* * *} \\
(0.009)\end{array}$ & $\begin{array}{l}-0.100^{* * *} \\
(0.005)\end{array}$ \\
\hline Observations & 226,329 & 24,297 & 215,536 & 109,307 & 119,715 \\
\hline $\begin{array}{l}\text { Avg } \log (\mathrm{PQ}) \\
\text { (b) Mobility }\end{array}$ & 8.400 & 9.100 & 8.360 & 8.099 & 8.667 \\
\hline Lockdown $_{i t}$ & $\begin{array}{l}-1.837^{* * *} \\
(0.059)\end{array}$ & $\begin{array}{l}-1.497^{* * *} \\
(0.170)\end{array}$ & $\begin{array}{l}-1.867^{* * *} \\
(0.058)\end{array}$ & $\begin{array}{l}-1.997^{* * *} \\
(0.085)\end{array}$ & $\begin{array}{l}-1.691^{* * *} \\
(0.076)\end{array}$ \\
\hline Observations & 226,329 & 24,297 & 215,536 & 109,307 & 119,715 \\
\hline Avg mob & 2.957 & 2.750 & 2.957 & 2.887 & 3.014 \\
\hline Time FE & $\checkmark$ & $\checkmark$ & $\checkmark$ & $\checkmark$ & $\checkmark$ \\
\hline Province/product FE & $\checkmark$ & $\checkmark$ & $\checkmark$ & $\checkmark$ & $\checkmark$ \\
\hline
\end{tabular}

Difference-in-differences results, as in Eq. (2), on log revenues (a) and mobility (b). In column 1 (Baseline) we use all available data and keep the control group as broad as possible. In column 2 we focus on a restrictive definitions of control group, using the nearest decile of distance from the epicenter. In column 3 (No Neighbors), we exclude from the sample the provinces contiguous to Lodi, while in columns 4 to 6 we compare Lodi to Southern and Central, or Northern provinces. In all models, we cluster the standard errors at the province and date level. $\operatorname{Avg} \log (P Q)$ and $A v g$ mob report the average (log) revenues and the average mobility measure in the sample, respectively

North), which we use as control group: all models yield very robust results for both outcomes.

In Table 5, we run the baseline exercise by product group, both for revenues (panel A), and for its main component, quantity (panel B). As expected, the product dimension provides an interesting source of heterogeneity: for instance, the estimated parameters for Food and Medical equipment are significantly lower in absolute value than the aggregate model ones, indicating a lower elasticity of demand for goods deemed as "more essential", even in the quarantined zones. Consistently, coefficients referred to Soft Drinks and Personal Appliances are higher in absolute value ( -12 and $-19 \%$, respectively): when forced to limit their shopping trips, consumers choose to reduce their consumption of those products. Finally, the quantity channel is the one driving the estimates: apart from the Household products, the estimates virtually don't change when using $Q_{i p t}$ instead of $P Q_{i p t}$.

\subsection{The Contagion Risk Effect}

The estimate of the lockdown effect does not provide information on the objective risk of contagion. Even in the absence of direct restrictions to personal mobility, in fact, customers may decide to loose their shopping habits and avoid social contacts while shopping the stores. On the other hand, a higher contagion risk may lead to higher levels of precautionary spending and stockpile shopping, because of the uncertainty 
Table 5 Difference-in-differences: results per product

\begin{tabular}{|c|c|c|c|c|c|c|c|}
\hline & Overall & Food & S Drinks & Alcohol & Medic & Household & Personal \\
\hline \multicolumn{8}{|c|}{ Panel (A) Revenues } \\
\hline Lockdown $_{i t}$ & $\begin{array}{l}-0.106^{* * *} \\
(0.002)\end{array}$ & $\begin{array}{l}-0.096^{* * *} \\
(0.003)\end{array}$ & $\begin{array}{l}-0.121^{* * *} \\
(0.003)\end{array}$ & $\begin{array}{l}-0.080^{* * *} \\
(0.006)\end{array}$ & $\begin{array}{l}-0.037^{* * *} \\
(0.004)\end{array}$ & $\begin{array}{l}-0.000 \\
(0.009)\end{array}$ & $\begin{array}{l}-0.160^{* * *} \\
(0.005)\end{array}$ \\
\hline Observations & 226,329 & 136,925 & 17,023 & 5675 & 19,697 & 2064 & 33,088 \\
\hline Avg $\log (\mathrm{PQ})$ & 8.400 & 8.535 & 8.746 & 8.983 & 7.739 & 8.862 & 7.808 \\
\hline \multicolumn{8}{|c|}{ Panel B) Quantity } \\
\hline Lockdown $_{i t}$ & $\begin{array}{l}-0.104^{* * *} \\
(0.002)\end{array}$ & $\begin{array}{l}-0.095^{* * *} \\
(0.003)\end{array}$ & $\begin{array}{l}-0.133^{* * *} \\
(0.003)\end{array}$ & $\begin{array}{l}-0.071^{\text {*** }} \\
(0.006)\end{array}$ & $\begin{array}{l}-0.027^{* * *} \\
(0.004)\end{array}$ & $\begin{array}{l}0.036^{* * *} \\
(0.008)\end{array}$ & $\begin{array}{l}-0.150^{* * *} \\
(0.005)\end{array}$ \\
\hline Observations & 226,306 & 136,902 & 17,023 & 5675 & 19,697 & 2064 & 33,088 \\
\hline Avg $\log (\mathrm{Q})$ & 6.856 & 6.695 & 7.537 & 7.151 & 6.939 & 7.367 & 6.691 \\
\hline Time FE & $\checkmark$ & $\checkmark$ & $\checkmark$ & $\checkmark$ & $\checkmark$ & $\checkmark$ & $\checkmark$ \\
\hline $\begin{array}{l}\text { Province/produ } \\
\text { FE }\end{array}$ & & $\checkmark$ & $\checkmark$ & $\checkmark$ & $\checkmark$ & $\checkmark$ & $\checkmark$ \\
\hline
\end{tabular}

panel a) Difference-in-differences results, as in Eq. (2), run per product group. Column 1 reports the baseline estimates, whereas in columns 2 to 7 we restrict the estimation sample to the individual product groups. Panel b) Difference-in-differences results, as in Eq. (2), run per product group and on quantity demanded. In all models, we cluster the standard errors at the province level

related to the evolution of the pandemics, to supply capacity of stores, and to the regulatory measures. In this context, the lockdown imposed on February, 23rd in Lodi signalled the urgency and magnitude of the sanitary crisis across the country, irrespective of the objective contagion risk faced (i.e., $\beta_{\text {highRisk }}^{\text {sign }}=\beta_{\text {lowRisk }}^{\text {sign }}$ ). We test this conjecture by both exploiting the geographical variation of infection rate and the regulatory interventions that followed the partial lockdown. First, we exclude Lodi from the analysis (because subject to mobility restrictions, too) and we partition the provinces into treated and control units depending on the physical distance from the epicenter. More specifically, we use the provinces neighboring Lodi as the treatment group, given that they faced the highest contagion risk. The second approach follows from the definition of Red Zone provided by the government 2 days before declaring the nationwide lockdown: we define the treatment group accordingly.

We then compare treatment and control group(s) by applying model (2) to obtain estimates of the contagion risk effect only, as long as neither group was subject to any restriction to the mobility, and all differences in revenues must be attributed to the differential contagion risk that informs the definition of treatment. The results are shown in Table 6, for both Neighbor provinces (columns 1 to 4) and Red Zone provinces (columns 5 to 8 ). There is no statistically significant difference in any of the group. More specifically, $\beta_{\text {highRisk }}^{\text {sign }}-\beta_{\text {lowRisk }}^{\text {sign }}=0$ independently of the control group we choose, whether it be the whole sample (Baseline), the provinces belonging to the first decile of distance from the epicenter (Nearest Neighbors, marked by the solid blue line in Fig. 10), all the Southern and Central provinces (Treated vs. Center-South) or the sole Northern provinces (Treated vs. North). This robust evidence also serves as 
Table 6 Results of alternative treatment

\begin{tabular}{|c|c|c|c|c|c|c|c|c|}
\hline & \multicolumn{4}{|c|}{ Neighbor provinces } & \multicolumn{4}{|c|}{$\underline{\text { Red zone provinces }}$} \\
\hline & Baseline & $\begin{array}{l}\text { Nearest } \\
\text { Neighbors }\end{array}$ & $\begin{array}{l}\text { Treated } \\
\text { vs. } \\
\text { Center- } \\
\text { South }\end{array}$ & $\begin{array}{l}\text { Treated } \\
\text { vs. North }\end{array}$ & Baseline & $\begin{array}{l}\text { Nearest } \\
\text { Neighbors }\end{array}$ & $\begin{array}{l}\text { Treated } \\
\text { vs. } \\
\text { Center- } \\
\text { South }\end{array}$ & $\begin{array}{l}\text { Treated } \\
\text { vs. } \\
\text { North }\end{array}$ \\
\hline Lockdown $_{i t}$ & $\begin{array}{l}-0.022 \\
(0.036)\end{array}$ & $\begin{array}{l}-0.008 \\
(0.024)\end{array}$ & $\begin{array}{l}-0.027 \\
(0.046)\end{array}$ & $\begin{array}{l}-0.016 \\
(0.028)\end{array}$ & $\begin{array}{l}-0.009 \\
(0.024)\end{array}$ & $\begin{array}{l}- \\
-\end{array}$ & $\begin{array}{l}-0.014 \\
(0.032)\end{array}$ & $\begin{array}{l}0.000 \\
(0.010)\end{array}$ \\
\hline Observations & 223,636 & 21,604 & 117,407 & 117,022 & 223,636 & 64,246 & 168,230 & 119,652 \\
\hline Avg $\log (\mathrm{PQ})$ & 8.404 & 9.229 & 8.201 & 8.681 & 8.404 & 8.839 & 8.380 & 8.671 \\
\hline Time FE & $\checkmark$ & $\checkmark$ & $\checkmark$ & $\checkmark$ & $\checkmark$ & $\checkmark$ & $\checkmark$ & $\checkmark$ \\
\hline $\begin{array}{l}\text { Province/product } \\
\text { FE }\end{array}$ & $\checkmark$ & $\checkmark$ & $\checkmark$ & $\checkmark$ & $\checkmark$ & $\checkmark$ & $\checkmark$ & $\checkmark$ \\
\hline
\end{tabular}

Difference-in-differences results, as in Eq. (2). The treatment group are the provinces contiguous to Lodi (Neighbor Provinces, columns 1 to 4) or the Red Zone provinces (columns 5 to 8)-Lodi is excluded from the sample. Column 1 (5) reports the baseline estimates. In column 2 (6) we focus on a restrictive definitions of control group, using the nearest decile of distance from the epicenter, while in columns 3 and 4 ( 7 and 8) we compare Lodi to Southern and Central, or Northern provinces, respectively. In all models, we cluster the standard errors at the province and date level. $\operatorname{Avg} \log (P Q)$ reports the average $(\log )$ revenues in the sample

a placebo test to supports our identifying assumption by confirming that there is no detectable difference in the signalling effect across the country.

\section{Conclusions}

The grocery chain stores have played a crucial role during the first wave of the Covid19 pandemics. The sector faced a huge positive demand shock for most product categories - which means, in turn, being able to cope with shortages, adjust the logistics, increase hours and working shifts, all of it right in the middle of an unprecedented crisis, which raised uncertainty and blocked most economic activities. As the Covid 19 is becoming endemic, it is likely to require recurrent restrictions in order to prevent the spreading of contagion: hence, understanding the effects of containment measures on new consumption habits and therefore on retailers' performance has become of first-order importance.

This paper contributes by showing that even in sectors not subject to extreme shut down policies, as it has been the case for grocery retailers (i) lockdown measures curb revenue increases by a considerable amount; in particular, they do so through the mobility channel, which mainly affects larger peripheral outlets, whose revenues were around $10 \%$ lower than those in their control group; (ii) the contagion risk plays a minor role, its effects being homogeneous across provinces; (iii) changes in quantity purchased, rather than price movements, drive most of the revenue dynamics; (iv) there exist huge variations in both quantity demanded, prices charged and dynamic response across areas and outlet types. 


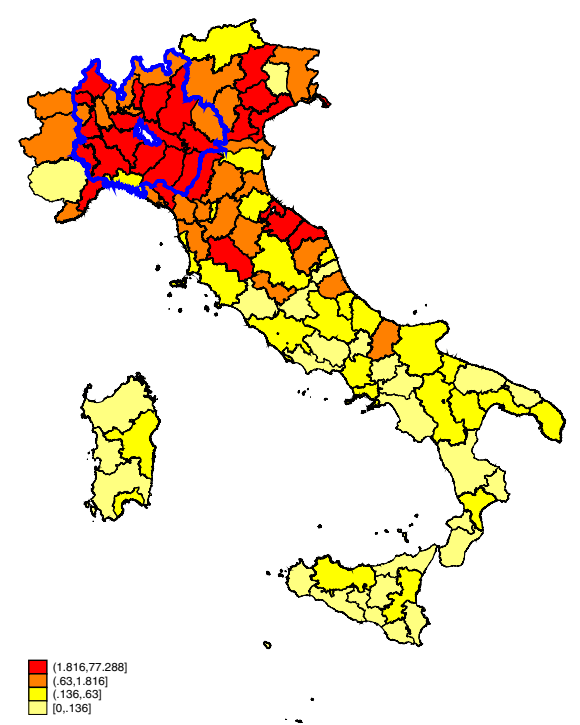

Notes: Total Covid-19 identified cases between March and September, 2020, per 100,000 inhabitants at the province level (February/August, 2020). The province of Lodi is in white; the solid blue lines mark all provinces within the first quartile of dsitance from Lodi.

Fig. 10 Total cases over 100,000 provincial population (color figure online)

\section{Appendices}

\section{Appendix A: The Evolution of the Pandemics in Italy}

The evolution of the "first wave" of Covid-19 pandemics in Italy is reported in Fig. 11a. In particular, we plot the total number of cases_-dashed blue line — and the number of new cases recorded-solid red line. The dashed vertical lines mark the starting (red) and ending (black) dates of the national lockdown. The number of cases peaked a few days after the regulatory measures, and slowly decreased afterwards: during the summer, the "respite" period has been characterized by a very low number of new infections. Panel (b) reports the geographical dispersion of the incidence across provinces-i.e., the total number of cases over total population-during the first wave.

The two plots highlight the main features of the pandemics in Italy: first, its impact peaked during the lockdown, whereas the rate of infections was sensibly lower from May on, second, it was characterized by a strong local variation: while all provinces recorded at least a few cases, by far the most hit places were located in the northwestern regions (Lodi, Bergamo, Milano) which experienced the worst consequences in terms of lost lives and healthcare systems collapses. 
(a) Country-level new and total cases

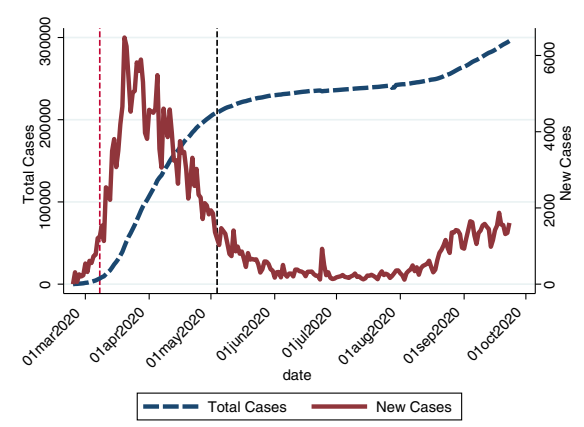

(b) Incidence over provincial population

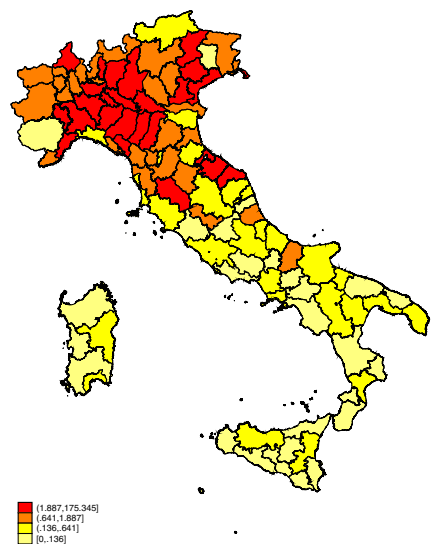

Notes: (a) total number of cases (dashed blue line) and daily number of new cases (solid red line) in Italy between February, 23 and September 30, 2020. Vertical dashed lines mark the national lockdown dates (b) geographical variation of first-wave incidence (defined as the ratio between the total number of cases and the province population).

Fig. 11 Covid-19 evolution in Italy (color figure online)

\section{Appendix B: Descriptive Analysis: The Lockdown Effect}

The descriptive evidence shown in Fig. 7, although extremely informative, fails to address more specific questions related to the quantification of the lockdown effect, and does not account for the differentials between Northern and Southern regions. In order to shed further light on these features, we propose a simple fixed effects linear regression model, aimed at capturing the impact of the pandemics on product revenues for each sub-period. More specifically, we run a fixed-effects regression of product revenues (in logarithms) of the following form

$$
y_{i, w, r, s}=\beta L_{w}+\gamma_{k}+\tau_{t}+\alpha_{r}+\sigma_{s}\left[+\psi_{i}\right]+\epsilon_{i, w, r, s}
$$

where $i, w, a, k$, and $s$ represent the product, the week, the region and the store type, respectively. $L_{w}$ is an indicator function for the weeks from March 9 to May 4, 2020, and captures the gross effect of the lockdown period on product revenues, net of all factors related to the specific period of the year $\left(\tau_{t}=\right.$ week $_{t}+$ mont $_{t}+$ year , which controls for week of the year, month of the year, and year fixed effects), macro-region characteristics $\left(\alpha_{r}\right)$, store type $\left(\sigma_{s}\right)$ and product group specificity $\left(\gamma_{k}\right.$ in the baseline model, replaced by $\psi_{i}$-i.e., product fixed effects - in a more saturated specification). We augment model (3) in several ways. First, we add indicator functions to capture the anticipation effect $\left(A_{i, w, r, s}\right.$, active between Feb 1 and Mar 8, 2020) and the respite period $\left(R_{i, w, r, s}\right.$, since the lockdown end)-i.e., All Periods model:

$$
y_{i, w, r, s}=\beta L_{w}+\delta A_{i, w, r, s}+\eta R_{i, w, r, s}+\gamma_{k}+\tau_{t}+\alpha_{r}+\sigma_{s}\left[+\psi_{i}\right]+\epsilon_{i, w, r, s}
$$


Table 7 Regression results

\begin{tabular}{llllll}
\hline & Base & Time & ST+Clust & All & Prod \\
\hline $\begin{array}{lllll}\text { Model (1): Baseline } \\
\text { Lockdown }\end{array}$ & $0.025^{* * *}$ & $0.023^{*}$ & $0.024^{*}$ & $0.025^{*}$ & $0.019^{* *}$ \\
& $(0.010)$ & $(0.013)$ & $(0.013)$ & $(0.013)$ & $(0.008)$ \\
Model (2): All periods & & & & \\
Lockdown & $0.039^{* * *}$ & $0.033^{*}$ & $0.033^{*}$ & $0.038^{* *}$ & $0.023^{* *}$ \\
& $(0.010)$ & $(0.018)$ & $(0.018)$ & $(0.018)$ & $(0.011)$ \\
Anticipation & $-0.107^{* * *}$ & $-0.071^{* * *}$ & $-0.066^{* * *}$ & $-0.041^{* *}$ & $-0.044^{* * *}$ \\
& $(0.012)$ & $(0.019)$ & $(0.019)$ & $(0.019)$ & $(0.012)$ \\
Respite & $0.038^{* * *}$ & 0.021 & 0.020 & 0.023 & 0.010 \\
Observations & $(0.007)$ & $(0.018)$ & $(0.017)$ & $(0.017)$ & $(0.010)$ \\
Time FE & $1,079,654$ & $1,079,654$ & $1,079,654$ & $1,050,004$ & $1,050,004$ \\
Area FE & & $\checkmark$ & $\checkmark$ & $\checkmark$ & $\checkmark$ \\
Product group FE & & & $\checkmark$ & $\checkmark$ & $\checkmark$ \\
Store type FE & & & & $\checkmark$ & $\checkmark$ \\
Product FE & & & & $\checkmark$ \\
\hline
\end{tabular}

(1) Estimated results of model (3) with increasing number of fixed effects: week (column 2), area (column 3), the product class and the store type (column 4), and the individual products (column 5). (2) Estimated results of model (4) with increasing number of fixed effects

Table 7 reports the results: the estimated $\beta$ s are all positive and statistically significant, although less and less as we add fixed effects. Notice that in the All periods specification, the estimated lockdown effect gets reduced by about a half when controlling for each individual product instead of product group (column Prod). Thus, the extent of within-product group variation is an important driver of revenue growth. Despite the generally positive trend, we retrieve a negative Anticipation parameter $(\hat{\delta})$. The latter seems to indicate that, conditioning on product, area, and outlet type fixed effects, revenues decreased in the weeks immediately preceding the restrictions. Accordingly, this result could hinge on a pattern of spending substitution towards products already highly represented within the consumption basket (e.g., bottled water, canned goods), at the expenses of products unaffected by precautionary stockpiling (e.g. cosmetics and perishables), which experienced a significant reduction. Finally, the Respite parameter $(\hat{\eta})$ is never statistically significant, in line with the descriptive evidence.

In order to further investigate how the heterogeneous within-group patterns and the difference across store types drive the lockdown effects, we conduct an analysis at the individual product level and implement two sequential exercises. First, we descriptively quantify the lockdown effect on sold quantities by regressing their $(\log )$ value on an indicator for the lockdown period. The estimated model, run product by product, writes

$$
q_{t}=\alpha+\beta_{q} L_{t}+\epsilon_{t}
$$


(a) Lockdown effect per product

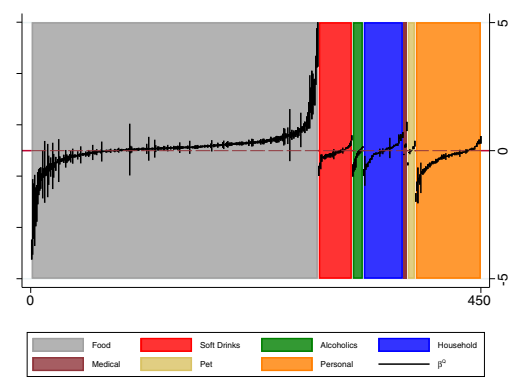

(b) Lockdown effect density per store type

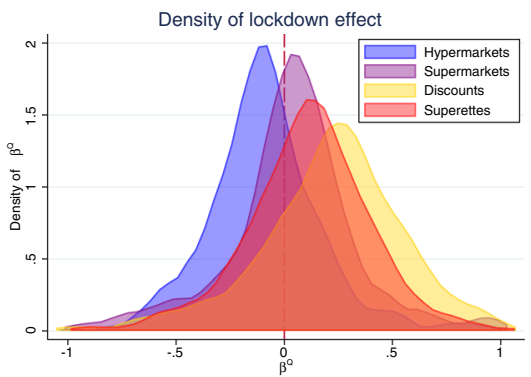

Notes: (a) Distribution of the lockdown effect on quantity purchased per product $\left(\hat{\beta}^{Q}\right.$ as defined in (5)). Estimated parameters are sorted in ascending order. The horizontal line is set at $\hat{\beta}^{Q}=0$ (b) Density distributions of the lockdown effect on quantity purchased per store type $\left(\hat{\beta}^{Q}\right.$ as defined in (5)). The vertical line is set at $\hat{\beta}^{Q}=0$.

Fig. 12 Lockdown estimated effect per product and store type (color figure online)

where $q_{t}$ is the log of total quantity sold at time $t$, summed across NUTS 1 regions and distributive channels, and $L_{t}$ is an indicator function equal to 1 for the lockdown weeks and zero otherwise. Thus, the coefficient $\beta_{q}$ captures the dynamics observed during the restriction period. It is crucial to stress that such effect is averaged across all areas and distributive channels, and provides an indication of the overall "appeal" of individual products between March and May. In Fig. 12a, we plot all the 450 estimated $\beta_{q}-$ with their confidence intervals - divided by product category. Results, as expected, show a high degree of heterogeneity across and within categories-e.g., on average, Food products show marked increases, whereas Personal Care goods have usually recorded less sustained growth, except for hygiene-related products, whose request surged, following recommendation on hygiene protocols to limit contagion.

Second, we further investigate the differences in quantity demanded among products, conditional on store types, by looking at the distribution of the product-store fixed effects interacted with the lockdown period indicator. In formulas, we estimate a fixed effects model of the form

$$
r(q)_{w}=\text { lockdown } \times \psi_{i} \times \sigma_{s}
$$

where lockdown $\times \psi_{i} \times \sigma_{s}$ is an interaction term that captures the combined (fixed) effects of store types, individual products, and the lockdown period. Such a saturated model yields $462 \times 4=1848$ parameters for the baseline estimate, and likewise for the lockdown period. In order to find the lockdown net effect for each product/store couple, we subtract one another, and in Fig. 12b, we plot the resulting densities. The results confirm a massive detrimental effect of the lockdown on hypermarkets, where most products show negative fluctuations (i.e., estimates below zero) during the mobility restriction period, whereas supermarkets, superettes and mostly discounts faced positive demand shocks. 


\section{Appendix C: The Effect of the Lockdown}

The length of the available data allows us to check the robustness of the year-onyear changes reported in Fig. 7a. Indeed, a similar picture can be retrieved by using data on 2018 revenues (Fig. 13a), which supports the hypothesis that the 2020 revenue dynamics were actually abnormally high with respect to previous periods. A further test for robustness is provided in panel (b), where we plot $r(y)$ referring to the 2019 series ("control" sample): aside from increases due to Easter dates, there is no detectable trend in the series, as expected.

In Table 8 we analyze the three time intervals individually, for each adjusted series (i.e., $r(y), r^{2}(y)$ and $r(y) 2019$ vs. 2018). We report their sum, period by period, in levels (first three rows, in million $€$ ) and in percentage change for the full period (fourth row). Results confirm that the pandemic period dramatically affected total revenues of the GDO. Despite a very modest increase between 2019 and 2018-amounting to about $2 \%$ for the whole period, column 3-the effect of the pandemics is clearly identified both by contrasting the 2020 revenues with those in $2019(+11.3 \%)$, and with those in $2018(+13.6 \%)$. The most striking difference between the 2020 and

(a) 2020 vs. 2018

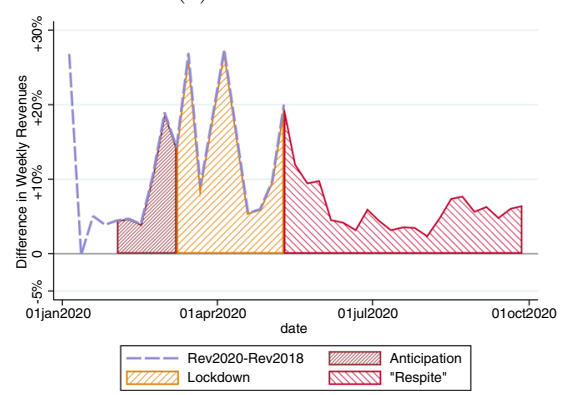

(b) 2019 vs. 2018

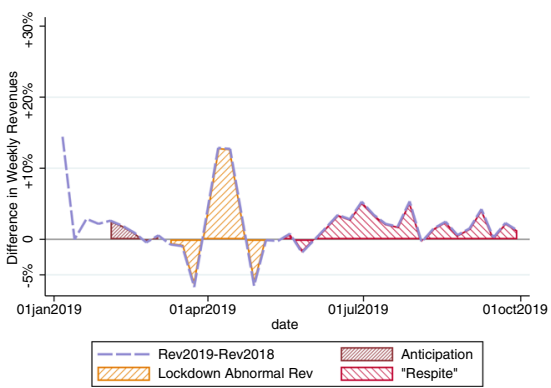

Notes: (a) Year-on-two-years \% changes in revenues split in subperiods - Anticipation in maroon, Lockdown in yellow, and Respite in red. (b) Year-on-year \% changes in revenues split in subperiods - Anticipation in maroon, Lockdown in yellow, and Respite in red - relative to the confront between 2019 and 2018.

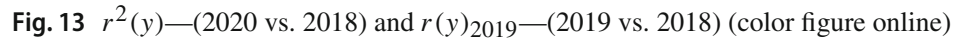

Table 8 Empirical distribution of $r(y)$ and $r^{2}(y)$-all periods

\begin{tabular}{llll}
\hline & Treated & Control \\
\cline { 2 - 4 } & $y^{2020}-y^{2019}$ & $y^{2020}-y^{2018}$ & $\frac{y^{2019}-y^{2018}}{133}$ \\
\hline Anticipation (mln $€$ ) (Feb 1-Mar 8) & 689 & 824 & 322 \\
Lockdown (mln €) (Mar 9-May 9) & 1.818 & 2.141 & 17 \\
Respite (mln $€$ ) (May 10-Sep30) & 560 & 578 & 2 \\
Full period (\% change) (Feb 1-Sep30) & 11.3 & 13.6 & 2
\end{tabular}

Sum of $r(y)$ (columns 1 and 3$)$ and $r^{2}(y)$ (column 2) per period, in million euros. The Full period figure is reported in \% change 
Table 9 Regression results

\begin{tabular}{|c|c|c|c|c|}
\hline & Area & Store & Cluster & All \\
\hline \multicolumn{5}{|l|}{ Model (3): Marginal effects } \\
\hline Lockdown $\times$ NorthWest & $\begin{array}{l}0.090^{* * *} \\
(0.021)\end{array}$ & & & $\begin{array}{l}0.580^{* * *} \\
(0.034)\end{array}$ \\
\hline Lockdown $\times$ NorthEast & $\begin{array}{l}-0.044^{* *} \\
(0.022)\end{array}$ & & & $\begin{array}{l}0.162^{* * *} \\
(0.034)\end{array}$ \\
\hline Lockdown $\times$ Center + Sardinia & $\begin{array}{l}0.002 \\
(0.022)\end{array}$ & & & $\begin{array}{l}0.199 * * * \\
(0.034)\end{array}$ \\
\hline Lockdown $\times$ South + Sicily & $\begin{array}{l}-0.595^{* * *} \\
(0.021)\end{array}$ & & & $\begin{array}{l}-0.126^{* * *} \\
(0.034)\end{array}$ \\
\hline Lockdown $\times$ Discount & & $\begin{array}{l}0.107^{* * *} \\
(0.021)\end{array}$ & & $\begin{array}{l}-0.803^{* * *} \\
(0.026)\end{array}$ \\
\hline Lockdown $\times$ Drugstore & & $\begin{array}{l}-2.183^{* * *} \\
(0.037)\end{array}$ & & $\begin{array}{l}-3.039^{* * *} \\
(0.042)\end{array}$ \\
\hline Lockdown $\times$ Iper & & $\begin{array}{l}0.173^{* * *} \\
(0.021)\end{array}$ & & $\begin{array}{l}-0.727^{* * *} \\
(0.026)\end{array}$ \\
\hline Lockdown $\times$ Free Services & & $\begin{array}{l}-0.327^{* * *} \\
(0.021)\end{array}$ & & $\begin{array}{l}-1.235^{* * *} \\
(0.026)\end{array}$ \\
\hline Lockdown $\times$ Super & & $\begin{array}{l}0.905^{* * *} \\
(0.021)\end{array}$ & & $\begin{array}{l}0.000 \\
(.)\end{array}$ \\
\hline Lockdown $\times$ Food & & & $\begin{array}{l}0.090^{* * *} \\
(0.015)\end{array}$ & $\begin{array}{l}0.486^{* * *} \\
(0.026)\end{array}$ \\
\hline Lockdown $\times$ Soft Drinks & & & $\begin{array}{l}0.129^{* * *} \\
(0.035)\end{array}$ & $\begin{array}{l}0.599^{* * *} \\
(0.040)\end{array}$ \\
\hline Lockdown $\times$ Alcoholics & & & $\begin{array}{l}0.577^{* * *} \\
(0.061)\end{array}$ & $\begin{array}{l}0.961^{* * *} \\
(0.062)\end{array}$ \\
\hline Lockdown $\times$ Household Equipment & & & $\begin{array}{l}-0.248^{* * *} \\
(0.032)\end{array}$ & $\begin{array}{l}0.325^{* * *} \\
(0.037)\end{array}$ \\
\hline Lockdown $\times$ Medical Appliances & & & $\begin{array}{l}0.377^{* * *} \\
(0.096)\end{array}$ & $\begin{array}{l}0.950^{* * *} \\
(0.094)\end{array}$ \\
\hline Lockdown $\times$ Pet Products & & & $\begin{array}{l}-0.258^{* * *} \\
(0.068)\end{array}$ & $\begin{array}{l}0.315^{* * *} \\
(0.069)\end{array}$ \\
\hline Lockdown $\times$ Personal Care & & & $\begin{array}{l}-0.575^{* * *} \\
(0.026)\end{array}$ & $\begin{array}{l}0.000 \\
(.)\end{array}$ \\
\hline Observations & $1,079,654$ & $1,079,654$ & $1,050,004$ & $1,050,004$ \\
\hline$\tau_{t}$ & $\checkmark$ & $\checkmark$ & $\checkmark$ & $\checkmark$ \\
\hline$\alpha_{a}$ & $\checkmark$ & & & $\checkmark$ \\
\hline$\sigma_{s}$ & & $\checkmark$ & & $\checkmark$ \\
\hline$\gamma_{k}$ & & & $\checkmark$ & $\checkmark$ \\
\hline
\end{tabular}

Interacted estimated parameters of (3) for area (column 1), outlet type (column 2), product cluster (column 3 ) and all categories (column 4) indicators. We only report the parameter estimated for the lockdown period (i.e., lockdown = 1) 
Table 10 Regression results: store type

\begin{tabular}{|c|c|c|c|c|}
\hline & Discount & Hypermarket & Superette & Supermarket \\
\hline \multicolumn{5}{|c|}{ Panel (a): Store type analysis } \\
\hline Lockdown & $\begin{array}{l}0.026^{* * *} \\
(0.010)\end{array}$ & $\begin{array}{l}-0.162^{\text {*** }} \\
(0.009)\end{array}$ & $\begin{array}{l}0.212^{* * *} \\
(0.009)\end{array}$ & $\begin{array}{l}0.069^{* * *} \\
(0.009)\end{array}$ \\
\hline Observations & 249,859 & 257,831 & 253,708 & 258,213 \\
\hline \multicolumn{5}{|c|}{ Panel b): Interacted Coefficients } \\
\hline Lockdown & 0.118 & -0.169 & 0.193 & 0.100 \\
\hline Observations & $1,079,654$ & $1,079,654$ & $1,079,654$ & $1,079,654$ \\
\hline Time FE & $\checkmark$ & $\checkmark$ & $\checkmark$ & $\checkmark$ \\
\hline Area FE & $\checkmark$ & $\checkmark$ & $\checkmark$ & $\checkmark$ \\
\hline Product FE & $\checkmark$ & $\checkmark$ & $\checkmark$ & $\checkmark$ \\
\hline
\end{tabular}

(a) Estimated results of model (3) per store type. All estimated models include week, area, and individual product fixed effects. (b) Lockdown parameter estimates interacted with store type fixed effects: we report the difference between the lockdown and the no-lockdown periods estimates

the control series regards the "Respite" period: even after the end of the lockdown, abnormal revenues amount to more than $\times 33$ times those in the 2018-2019 period.

Finally, in Table 9 we report the estimated marginal effects of the full Eq. (3). More specifically, we interact the lockdown indicator function with indicator functions for areas (column 1), stores (column 2), product clusters (column 3), or full model (column 4 ), and report all estimates obtained for the lockdown period. Note that, in order to retrieve the full effect per category, one should subtract from the reported parameter the one obtained for lockdown $=0$ (see e.g. panel $b$ of Table 10).

\section{Appendix D: Robustness Checks}

Propensity score matching and weighting In order to relax the concern that our estimates are driven by unique features of the Lodi province, we both run a propensity score matching model and reweight the difference-in-difference model by the inverse of the propensity score: this way, we make sure that the estimation is driven more by provinces that are, ex-ante, more similar to Lodi, according to the chosen observables. More specifically, to estimate the propensity score we use measures related to both the physical/demographic characteristics and to the market structure whose relative weight might likely influence grocery chain stores revenues (data source in parenthesis):

\section{- Demography}

- share of population aged 75+ (Istat, 2019)

- population density in 2018 (Istat, 2018)

\section{- Market Structure}

- stores per kilometer (Asia/Istat, 2016)

- grocery chain stores employees per population (Nielsen, 2017) 
Table 11 Inverse propensity score weighting

\begin{tabular}{|c|c|c|c|c|}
\hline & \multicolumn{2}{|c|}{ Kernel-based PS } & \multirow{2}{*}{$\begin{array}{l}\text { IPW } \\
\text { ATE }\end{array}$} & \multirow{2}{*}{$\begin{array}{l}\text { PSM } \\
\text { ATE }\end{array}$} \\
\hline & ATT & ATE & & \\
\hline Treatment & $\begin{array}{l}-0.104 \text { *** } \\
(0.0061)\end{array}$ & $\begin{array}{l}-0.106^{* * *} \\
(0.00245)\end{array}$ & $\begin{array}{l}-0.105^{* * *} \\
(0.0200)\end{array}$ & $\begin{array}{l}-0.106^{* * *} \\
(0.0153)\end{array}$ \\
\hline $\mathrm{N}$ & 222,786 & 222,786 & 37,131 & 37,131 \\
\hline
\end{tabular}

Propensity score-weighted models using kernel-based weights for ATT (column 1) and ATE (column 2), inverse propensity score weighted (column 3) and propensity score matching difference-in-differences (column 4)

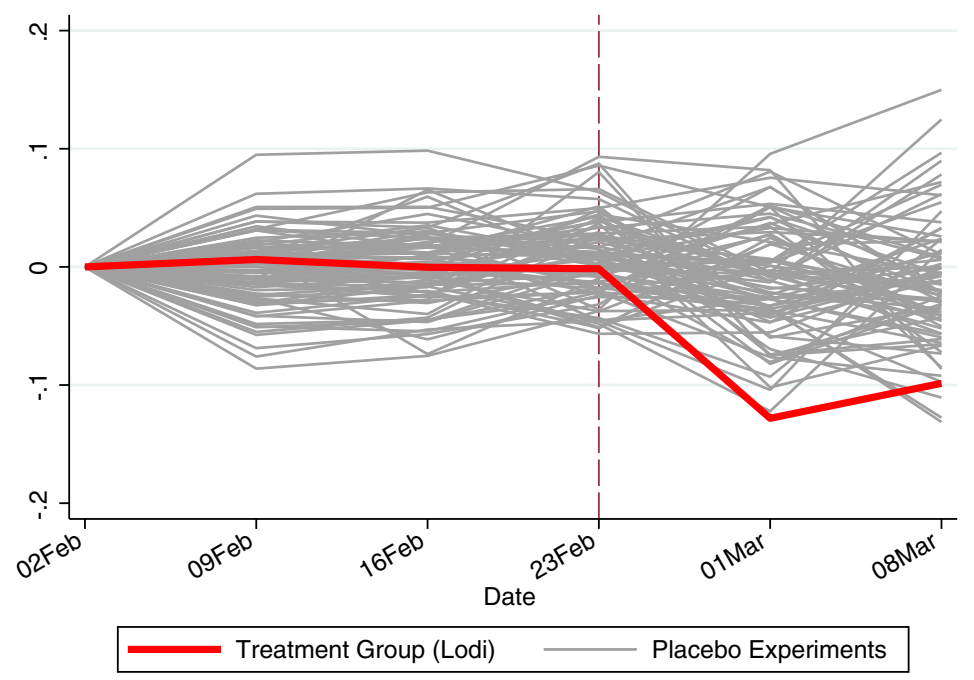

Notes: results of the estimated treatment effects in a synthetic control group approach (red line) contrasted with all available placebo exercises (gray lines).

Fig. 14 Inferential analysis: placebo Synthetic Control Group (color figure online)

Using the above variables, we are able to compute the propensity score at the province/product level, and run a full battery of robustness checks. The results, reported in Table 11, include propensity score-weighted models (using kernel-based weights for ATT, column 1, and ATE, column 2), the inverse propensity score weighted model (column 3) and a classical propensity score matching difference-in-differences (column 4). All of them are extremely robust with respect to the baseline results.

Synthetic control group analysis We use a similar approach to overcome the concerns related to the small number of treated units with respect to the control group product/provinces-in fact, a 1/86 ratio. To address this, we run a synthetic control group analysis: in a nutshell, we build a "synthetic Lodi province" using all provinces within the control group, reweighted in order to mimic the observables of the treated province. Once obtained the optimal weights, we confront the (untreated) synthetic Lodi with the actual Lodi, and estimate the effect of the treatment-with extremely 
robust results. We also repeat the same approach with all untreated provinces, and we use these placebo experiments to yield a sort of inferential analysis on the goodness of the results. Figure 14 reports the very satisfactory results: the counterfactual Lodi leads to a bigger drop in revenues (red line) with respect to all its placebo counterparts (grey lines).

\section{References}

Andersen AL, Hansen ET, Johannesen N, Sheridan A (2020) Consumer responses to the COVID-19 crisis: evidence from bank account transaction data. Available at SSRN 3609814

Baker SR, Farrokhnia RA, Meyer S, Pagel M, Yannelis C (2020a) How does household spending respond to an epidemic? consumption during the 2020 COVID-19 pandemic. Technical report. National Bureau of Economic Research, Cambridge

Baker SR, Farrokhnia RA, Meyer S, Pagel M, Yannelis C (2020b) Income, liquidity, and the consumption response to the 2020 economic stimulus payments. Technical report. National Bureau of Economic Research, Cambridge

Carvalho VM, Hansen S, Ortiz A, Garcia JR, Rodrigo T, Rodriguez Mora S, Ruiz de Aguirre P (2020) Tracking the COVID-19 crisis with high-resolution transaction data

Chronopoulos DK, Lukas M, Wilson JO (2020) Consumer spending responses to the COVID-19 pandemic: an assessment of Great Britain. Available at SSRN 3586723

Diao M, Leonard D, Sing TF (2017) Spatial-difference-in-differences models for impact of new mass rapid transit line on private housing values. Reg Sci Urban Econ 67:64-77

Goolsbee A, Syverson C (2020) Fear, lockdown, and diversion: comparing drivers of pandemic economic decline 2020. NBER Working Papers 27432, National Bureau of Economic Research, Cambridge

O'Connell M, de Paula A, Smith K (2020) Preparing for a pandemic: spending dynamics and panic buying during the COVID-19 first wave. CEPR Working Papers (15371)

Pepe E, Bajardi P, Gauvin L, Privitera F, Lake B, Cattuto C, Tizzoni M (2020) COVID-19 outbreak response, a dataset to assess mobility changes in Italy following national lockdown. Sci Data 7(1):1-7

Viviano E, Aimone Gigio L, Ciapanna E, Coin D, Colonna F, Lagna F, Santioni R (2012) The retail trade sector and the food industry in Italy. Bank of Italy Occasional Paper (119)

Publisher's Note Springer Nature remains neutral with regard to jurisdictional claims in published maps and institutional affiliations. 